\title{
Divergent pollination system and morph-dependent effects of corolla length on inaccuracy of reciprocity and reproductive success of a distylous species of Rubiaceae
}

\author{
Alessandra Ribeiro Pinto ${ }^{1,2 *}$ (1), Marina Muniz Moreira² (1), Miguel A. Rodríguez-Gironés ${ }^{3}$ (1) and Leandro Freitas ${ }^{2}$ (1)
}

Received: June 2, 2020

Accepted: February 5, 2021

\begin{abstract}
Intraspecific floral variations may affect the degree of generalization and efficacy of pollinators, with consequences for plant reproductive success. Such effects could be greater for heterostylous plants because morphological variation can alter reciprocity between morphs. We evaluated the frequency, composition, and efficacy of pollinators, and the reciprocity (measured by population inaccuracy) of Psychotria nuda, a distylous species of Rubiaceae, in a montane forest. Moreover, we assessed the effects of corolla length on reciprocity and reproductive success. We recorded eighteen species of floral visitors, belonging to four functional groups. The frequency of visits differed among groups with butterflies being the most frequent visitors, in contrast to hummingbird-pollinated lowland populations. This difference did not affect reproductive success, since fruit set was similar between these populations. The total population inaccuracy was $21.56 \mathrm{~mm}^{2}$, with inaccuracy of low organs being higher $\left(12.03 \mathrm{~mm}^{2}\right)$ than that of high organs $\left(9.53 \mathrm{~mm}^{2}\right)$. Floral traits may have different effects on the reproductive success of morphs of distylous species; the corolla length of $P$. nuda only affected the reproductive success of short-styled flowers. Large corollas showed greater reproductive success and lower individual inaccuracies for this morph, indicating compensation for the effects of imperfect reciprocal herkogamy on reproductive success.
\end{abstract}

Keywords: adaptative accuracy, Atlantic Forest, bees, butterflies, heterostyly, hummingbirds, reciprocal herkogamy

\section{Introduction}

Plants pollinated by animals have been classified as specialists or generalists based on the number of species or functional groups of pollinators (Ollerton et al. 2007). This classification is better represented by a specializationgeneralization gradient than by a simple dichotomy, with one extreme represented by plants pollinated by only one pollinator species or functional group, and the other by plants pollinated by a wide range of pollinators (Johnson \& Steiner 2000; Waser 2006; Ollerton et al. 2007). The degree of generalization of a plant is not only related to the number of floral visitors, but also to their pollination effectiveness (the efficacy in pollen transfer associated with frequency of visits; sensu Freitas 2013). Pollinator assemblages can also vary in space, potentially implying differences in floral morphology of plant populations of distinct geographic regions (Pérez-Barrales et al. 2007).

1 Programa de Pós-Graduação em Ecologia, Universidade Federal do Rio de Janeiro, 21941-902, Rio de Janeiro, RJ, Brazil

2 Jardim Botânico do Rio de Janeiro, 22460-040, Rio de Janeiro, RJ, Brazil

3 Estación Experimental de Zonas Áridas, 04120, La Cañada de San Urbano, Almeria, Spain

* Corresponding author: alessandraribeiropinto@gmail.com 


\section{Divergent pollination system and morph-dependent effects of corolla length on inaccuracy of reciprocity and reproductive success of a distylous species of Rubiaceae}

Variation in floral traits, such as floral display, size, color, odor, and rewards, may change the frequency and composition of floral visitors by shifts in floral attraction (Thompson 2001). The same trait may be attractive to some animals but not detectable or repulsive to others (Bergamo et al. 2016). Flowers may also present morphological barriers (e.g. long tubes) that prevent certain groups of visitors from legitimately accessing the floral resource (Santamaría \& Rodríguez-Gironés 2015). In addition to interspecific variation, floral traits can also vary intraspecifically, that is, among populations or individuals from the same population (Herrera 2009). In this way, pollinators may mediate selection in the evolution of floral traits (Harder \& Johnson 2009; Van der Niet \& Johnson 2012), if those traits are heritable and related to plant reproductive success (Navarro \& Guitián 2002).

Heterostyly is a floral polymorphism involving the spatial separation of the anthers and stigma, which can be expressed with two (distyly) or three (tristyly) floral morphs (Webb \& Lloyd 1986). In distyly, long-styled (LS) flowers possess high stigmas and low anthers, while short-styled (SS) flowers possess low stigmas and high anthers (Darwin 1877; Webb \& Lloyd 1986). This corresponding arrangement of the sexual organs between floral morphs is known as reciprocal herkogamy (Darwin 1877; Webb \& Lloyd 1986; Barrett 2002; Barrett \& Shore 2008). Distylous species usually present a heteromorphic self-incompatibility system, by which fruit production only occurs after disassortative pollination, i.e., precise intermorph pollen transfer (Barrett \& Richards 1990; Klein et al. 2009). Reciprocal herkogamy should favor cross-pollinations and may also avoid self-interference (i.e., between male and female sexual organs within individuals), a common conflict in monomorphic species pollinated by animals (Ganders 1979; Barrett et al. 2000; Barrett 2002). However, the performance of disassortative pollination can be influenced by several factors, such as morphological variation in floral traits, e.g. corolla length, anthers and stigma height, herkogamy (Keller et al. 2012; Sá et al. 2016; Furtado et al. 2021; Abdusalam et al. 2020) and shifts in the pollination system (Deschepper et al. 2018; Lehmann et al. 2019).

Corolla length of distylous plants may be one of the main factors affecting the degree of reciprocal herkogamy (or adaptive inaccuracy; sensu Armbruster et al. 2017), and consequently the performance of disassortative pollination (Furtado 2019). Corolla length can affect the height of anthers and stigma in distylous plants, and should present a stronger effect on anther height in distylous plants with epipetalous stamens (Keller et al. 2012; Sá et al. 2016). Moreover, distylous species may have morph-dependent effects on reproductive success, with distinct morphs responding differently to changes in floral traits, e.g. floral display, corolla width, floral tube length, nectar production (Li et al. 2017). Divergences in the pollination system among populations can also affect reciprocal herkogamy and reproductive success. A recent study involving different populations of a distylous species reported changes in the main pollinator, reduction in anther-stigma separation, and increase of selfing with increasing population altitude (Abdusalam et al. 2020). Therefore, morphological variation in floral traits and shifts in the pollination system of distylous species may affect reproductive success as a consequence of changes in the inaccuracy of sexual organs.

Rubiaceae has the greatest number of heterostylous species, with Psychotria L. being a typical distylous genus of the family (Hamilton 1990; Naiki 2012). Psychotria nuda (Cham. \& Schltdl.) Wawra is endemic to the Brazilian Atlantic Forest, where it occurs from sea level to montane forests (BFG 2015). Its flowers exhibit reciprocal herkogamy with large differences in the height of stigma and anthers, as well as in the length and diameter of the corolla (Klein 2007). Pollination studies of $P$. nuda have been carried out in lowland populations (up to $500 \mathrm{~m}$ a.s.l.), where different functional groups visit the flowers and hummingbirds are the main pollinators (Castro \& Araújo 2004; Almeida 2005). In addition, variation in floral traits (flower size and nectar volume) and environmental conditions (temperature and humidity) with elevation can influence the importance of insects or hummingbirds as pollinators of different species of Rubiaceae (Lehmann et al. 2019). In this study, we aimed to determine the composition, frequency, and efficacy of floral visitors in a population of $P$. nuda in a montane Atlantic forest (1100 $\mathrm{m}$ a.s.l.). We addressed the following questions: (1) Based on the frequency and efficacy of floral visitors, are hummingbirds the main pollinators of this population? (2) How reciprocal are the flowers, based on the measure of adaptive inaccuracies? (3) Does intraspecific variation in corolla length consistently affect the inaccuracy of reciprocity and reproductive success of each floral morph?

\section{Materials and methods}

\section{Study area and species}

We conducted the study between 2015 and 2017 in the municipality of Teresópolis, Rio de Janeiro State, Brazil, within "Parque Nacional da Serra dos Órgãos" (Serra dos Órgãos National Park - PARNASO; 22 ${ }^{\circ} 52^{\prime}$ - 22 $2^{\circ} 54^{\prime}$ S and $42^{\circ} 09^{\prime}-45^{\circ} 06^{\prime} \mathrm{W}$ ). The vegetation of the study site corresponds to evergreen montane forest (sensu Veloso et al. 1991) and the climate is tropical Cwb (i.e., tropical climate of altitude; Köppen \& Geiger 1928).

Psychotria nuda is a distylous shrub (ca. $5 \mathrm{~m}$ ) that usually blooms between February and June with a peak in April (Almeida \& Alves 2000; Castro \& Araújo 2004; Almeida 2005; Klein 2007). It presents a heteromorphic selfincompatibility system, which prevents or reduces self- and intra-morph fertilization by a sporophytically-controlled diallelic incompatibility system (see Klein et al. 2009). The flowers of $P$. nuda are grouped in cymose inflorescences commonly with three flowers but ranging from one to 
nine at the study site (Fig. 1A). The corolla is tubular and yellow (Fig. 1B-C). The calyx is red and persistent during fruit development (Fig. 1D). The fruit is a drupe and has a purple color when mature (Fig. 1D), after which the calyx falls. The androecium possesses five epipetalous stamens and anthers with longitudinal slits. The gynoecium has an inferior ovary with two ovules and a style with a bifid stigma. To conduct this study, we selected 52 individuals, 27 short-styled (SS; Fig. 1B) and 25 long-styled (LS; Fig. 1C), near the edge of "Primavera Trail" and along the main road inside PARNASO (ca. 1,050 - 1,100 m a.s.l.).

\section{Floral biology}

We registered floral traits in the field and in the laboratory, as follows: dimensions (corolla length, height of anthers and stigma; Fig. S1 in supplementary material) and nectar production. We measured 138 LS flowers from 19 individuals and 153 SS flowers from 19 individuals (one to 35 flowers per individual). To evaluate the nectar volume and concentration we bagged flowers at the pre-anthesis stage (LS $=56$ flowers from 10 individuals; $S S=51$ flowers from 12 individuals). We measured the nectar volume with
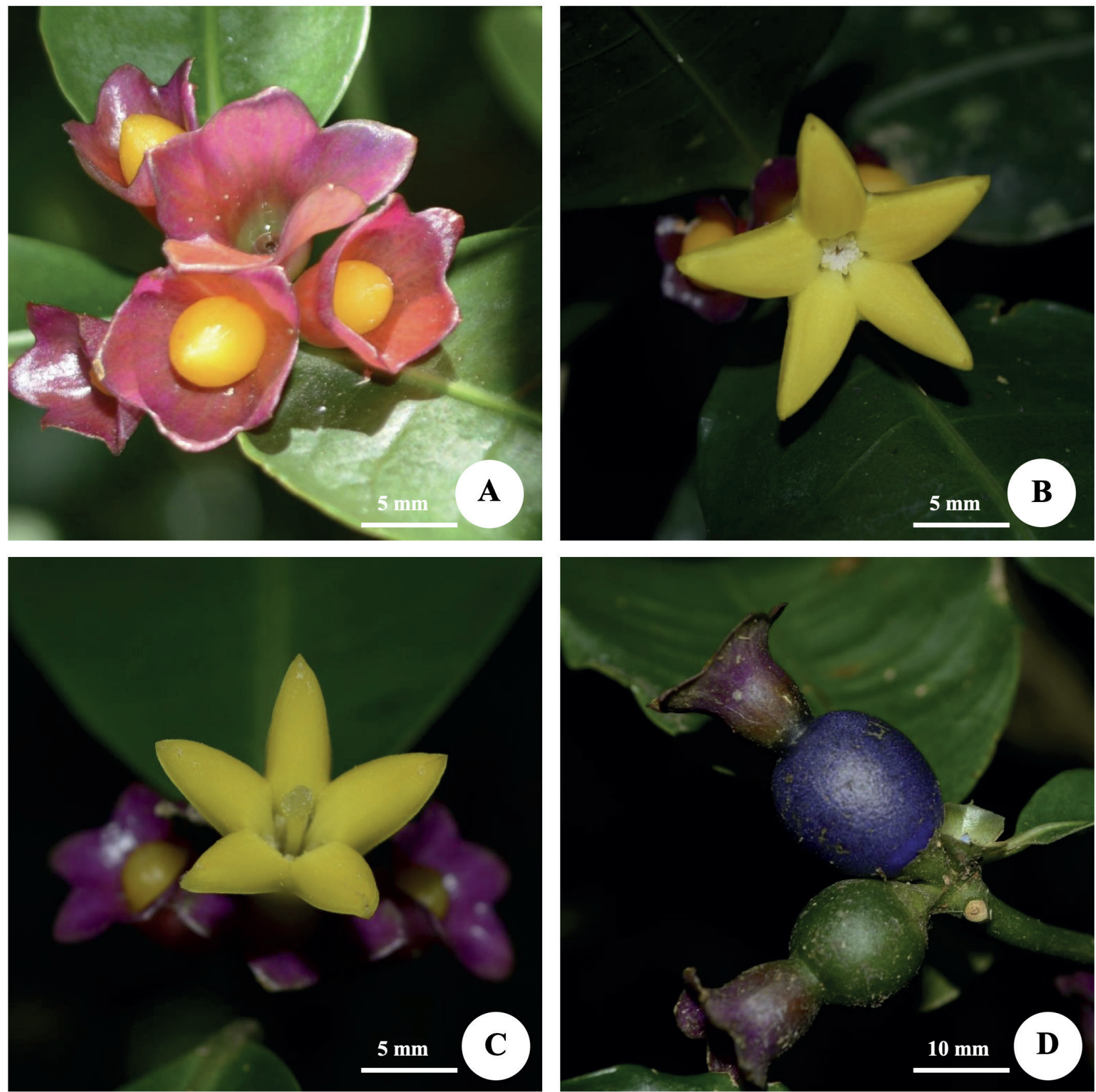

Figure 1. Flowers, buds, and fruits of Psychotria nuda in "Parque Nacional da Serra dos Órgãos" (PARNASO), Brazil: (A) Details of inflorescence with buds (B) short-styled (SS) flower; (C) long-styled (LS) flower; (D) Mature (purple) and immature (green) fruits. 


\section{Divergent pollination system and morph-dependent effects of corolla length on inaccuracy of reciprocity and reproductive success of a distylous species of Rubiaceae}

5- $\mu$ l glass microcapillary tubes and the concentration with a small-volume pocket refractometer (Eclipse, Bellingham + Stanley, UK). We conducted all the measures between 10:00 $\mathrm{h}$ and 12:00 $\mathrm{h}$.

\section{Inaccuracy of reciprocity}

We evaluated reciprocity between morphs in the population using the adaptive accuracy concept proposed by Armbruster et al. (2017), which considers inaccuracy as a measure of deviation from perfect reciprocity. For this calculation we used 19 flowers of each morph, with each flower coming from a different individual. We calculated population inaccuracy values for high and low organs as:

$$
\begin{gathered}
\text { Inaccuracy }_{\text {high organs }}=(\bar{A}-\bar{S})^{2}+V_{A}+V_{S} \\
\text { Inaccuracy }_{\text {low organs }}=(\bar{a}-\bar{s})^{2}+V_{a}+V_{s}
\end{gathered}
$$

where the height of high organs are represented by $A$ (anthers of SS) and $S$ (stigmas of LS), and the height of low organs are represented by $a$ (anthers of LS) and $s$ (stigmas of SS). $\bar{A}, \bar{S}, \bar{a}$ and $\bar{s}$ are averages and $V_{A}, V_{S}, V_{a}$ and $V_{s}$ are the variances. We calculated total population inaccuracy of reciprocity for the population as the sum of both low and high organs inaccuracies (Armbruster et al. 2017). Perfect reciprocity occurs if inaccuracy is zero, that is, if all corresponding anthers and stigmas are at the same position (optimal phenotype; Armbruster et al. 2017).

\section{Floral visitors}

To determine the richness of floral visitors and their frequency and behavior during visits we conducted focal observations through censuses of $30 \mathrm{~min}$ per individual for both morphs ( $\mathrm{LS}=11$ individuals; $\mathrm{SS}=10$ individuals). We conducted a total of $77 \mathrm{~h}$ of observations between $06: 00 \mathrm{~h}$ and 17:00h in 2015 (total $=32 \mathrm{~h} ; \mathrm{LS}=21 \mathrm{~h} ; \mathrm{SS}=11 \mathrm{~h}$ ) and 2016 (total $=45 \mathrm{~h} ; \mathrm{LS}=28 \mathrm{~h} ; \mathrm{SS}=17 \mathrm{~h}$ ). We considered the relative frequency of each functional group as the number of visits by a group divided by the total number of visits observed in the population, multiplied by 100 (\%).

We collected insects with an entomological net and we captured images of hummingbirds and insects during visits for later identification. We classified the floral visitors as legitimate or illegitimate (nectar robbing or thieving), according to their foraging behavior and capacity to contact reproductive structures (Inouye 1980). We also categorized the floral visitors among four functional groups based on body size and behavior during visits: butterflies, hummingbirds, large-sized bees (body length $\geq 12 \mathrm{~mm}$ ), and small-sized bees (< $12 \mathrm{~mm}$; Frankie et al. 1983).

\section{Pollinator efficacy}

We conducted treatments of selective exposure of flowers to pollinators to evaluate the efficacy of the different functional groups of pollinators on the female reproductive success (fruit set). As each flower has only two ovules and all fruits in our study had two seeds, we only used the fruit set to evaluate the reproductive success. Prior to treatments we bagged flowers in pre-anthesis stage with "voile" bags, which then we exposed when in anthesis to a single visit. After the visits, we bagged and marked the flowers for monitoring fruit development. We quantified fruit set after fruit maturation (i.e., when it changed from green to purple; Fig. 1D). We also counted flowers that did not produce fruits until complete senescence (named here as "non-fruits").

\section{Effect of corolla length on individual inaccuracy and reproductive success}

To evaluate the effect of corolla length on individual inaccuracy for each morph, we calculated individual female and male inaccuracies as: (female inaccuracies) the square of the difference between the height of an individual stigma and the mean height of compatible anthers of the population; (male inaccuracies) the square of the difference between the height of individual anthers and the mean height of compatible stigmas of the population (Jacquemyn et al. 2018).

Since the stamens are epipetalous, we measured the corolla length of 67 flowers of 18 individuals (SS $=32$ flowers, 7 individuals; LS = 35 flowers, 11 individuals) at anthesis. We marked and did not manipulate these flowers, and evaluated the fruit set to determine whether the corolla length can have an effect on fruit set under natural pollination.

\section{Data analyses}

We evaluated whether stigma and stamen height differed between morphs (LS and SS) using a linear mixed effect model. For this, we used the heights of the reproductive structures as response variables, the interaction of floral structures (two levels: stigma and anther heights) and floral morphs (two levels: LS and SS) as fixed effects and flower nested in individuals as a random effect. We established the model using the function "lmer" from the "lme4" package (Bates et al. 2015). To analyze whether corolla length differed between morphs, we performed Students $t$ test, using the function "t.test", and to evaluate whether nectar volume and concentration differed between the morphs, we used the Wilcoxon-Mann-Whitney non-parametric test using the function "wilcox.test".

We used a linear model to test whether the relative frequency of visits (\%) varied among the functional groups of floral visitors and between morphs. We considered groups (four levels: butterfly, hummingbird, large-bee, and smallbee) and morphs (two levels: LS and SS), as well as the interaction between these variables, as predictor variables. We compared the efficacy of groups of floral visitors through a chi-square test using the "chisq.test" function. 
We used linear models to evaluate whether corolla length has an effect on individual (female and male) inaccuracy. We tested whether inaccuracy values vary in relation to corolla length and morphs (LS and SS) using two different models. For this, we used inaccuracy (female or male) as response variables (square root transformed), and the interaction between the corolla length and floral morphs (two levels: LS and SS) as predictor variables. We evaluated whether corolla length is related to reproductive success (fruit set) through a generalized linear model for binomial data using the "glm" function. We considered corolla length and morph (two levels: LS and SS) as predictor variables.

We assessed model assumptions for all models by visual inspection of the residuals using the "qqnorm" function, and performed sum of squares (type III) using the "Anova" function of the "car" package (Fox \& Weisberg 2019). We also calculated differences between category levels using the "emmeans" package (Lenth 2019). We conducted all analyses in R v. 3.5.3 (R Development Core Team 2019).

\section{Results}

\section{Floral biology}

Anthesis started between 06:30h and 10:00h and lasted two to three days. The yellow corolla is tubular (LS length: $22.48 \pm 1.72 \mathrm{~mm}$; SS length: $24.89 \pm 1.96 \mathrm{~mm}$; mean \pm standard deviation, throughout the text), with five, rarely four or six, petals (Fig. 1B-C). Corolla length was shorter in LS morph $(\mathrm{t}=11.01 ; \mathrm{df}=288.68$; $\mathrm{p}<0.001$;

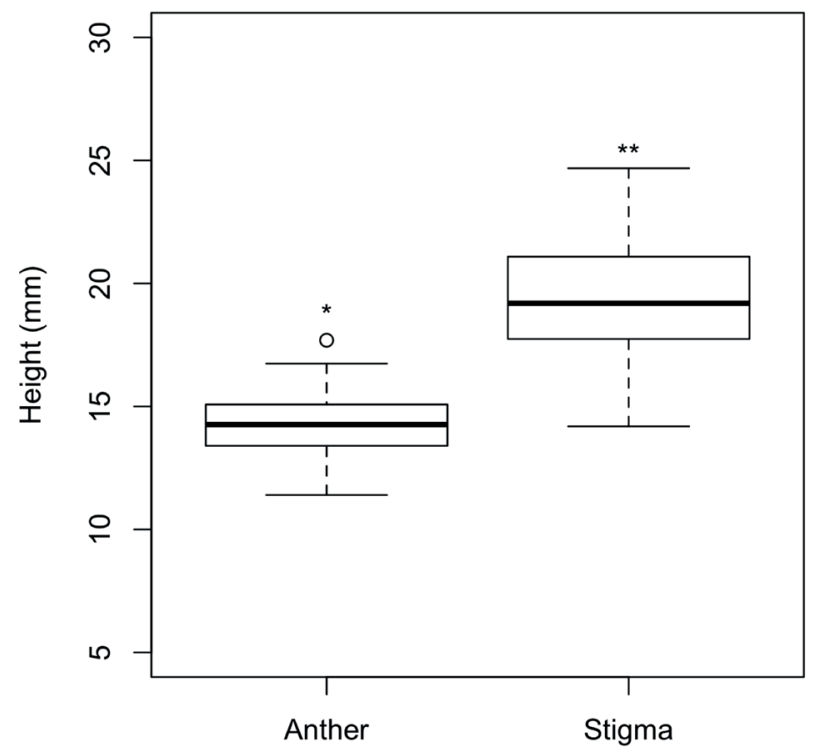

LS
Fig. S2 in supplementary material). Nectar was the main resource searched by floral visitors (volume $=12.26 \pm$ $11.95 \mu \mathrm{l}$; concentration $=17.52 \pm 6.63 \%)$. Nectar secretion did not differ between morphs (volume: $\mathrm{W}=1,297.00$; $p=0.42$; concentration: $W=1,428.00 ; p=0.99$; Fig. $S 3$ in supplementary material). On average the heights of anthers and stigma for plants differ within each morph (anthers and stigmas; $\mathrm{F}_{1,578}=1,060.36 ; \mathrm{p}<0.001$ ), and also among morph (LS and SS; $F_{1,578}=122.16 ; p<0.001$ ) with a significant interaction between these two factors (structure type: morph; $\mathrm{F}_{1,578}=3,216.54 ; \mathrm{p}<0.001$; Fig. 2; Tab. S1 in supplementary material).

\section{Inaccuracy of reciprocity}

The inaccuracy of reciprocity between the low organs was $12.03 \mathrm{~mm}^{2}$ and between the high organs it was 9.53 $\mathrm{mm}^{2}$, indicating lower reciprocity between the SS-stigmas and the LS-anthers (Fig. 2). The total inaccuracy of the population was $21.56 \mathrm{~mm}^{2}$.

\section{Floral visitors}

We registered a total of 18 species of floral visitors representing three orders: Apodiformes, Hymenoptera, and Lepidoptera (Fig. 3 and Tab. S2 in supplementary material). Most visitors (16 species) made legitimate visits (Fig. 3 and Tab. S2 in supplementary material). Apis mellifera and one unidentified species of butterfly (Nymphalidae, Ithomiini) acted exclusively as nectar larcenists by only collecting nectar through the calyx. Therefore, they were not included in the efficacy analyses. Most visits conducted by Trigona braueri were illegitimate, reflecting its reduced body and tongue

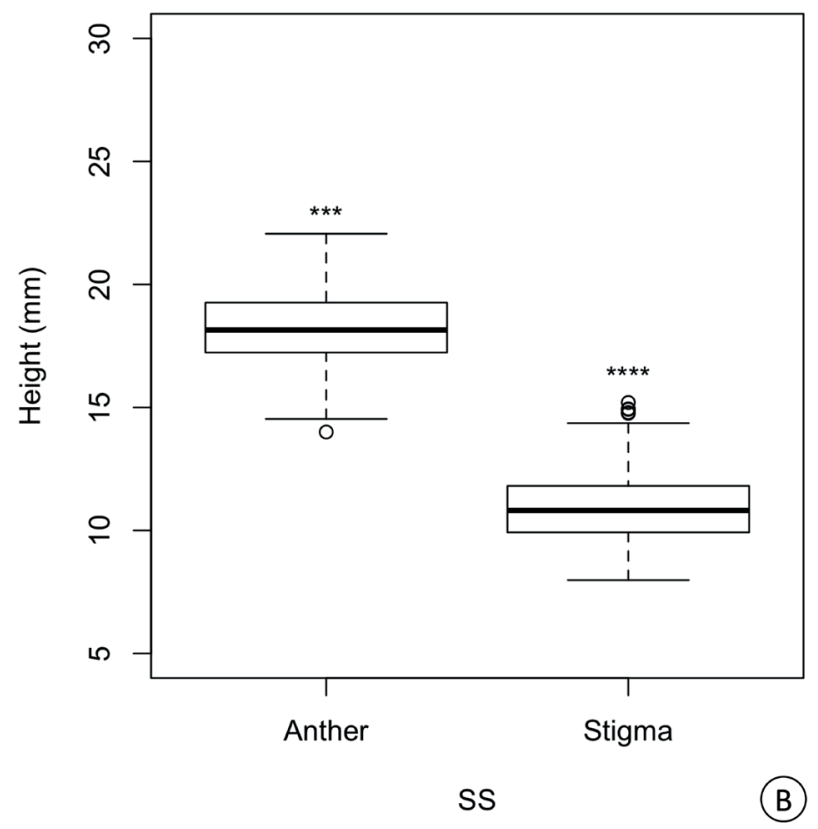

Figure 2. Height (mm) of anthers and stigma of Psychotria nuda flowers in "Parque Nacional da Serra dos Órgãos" (PARNASO), Brazil: (A) Reproductive structures of long-styled (LS) flowers; (B) Reproductive structures of short-styled (SS) flowers. Different symbols above boxes represent significant differences for pairwise comparisons $(\mathrm{p}<0.05)$. 

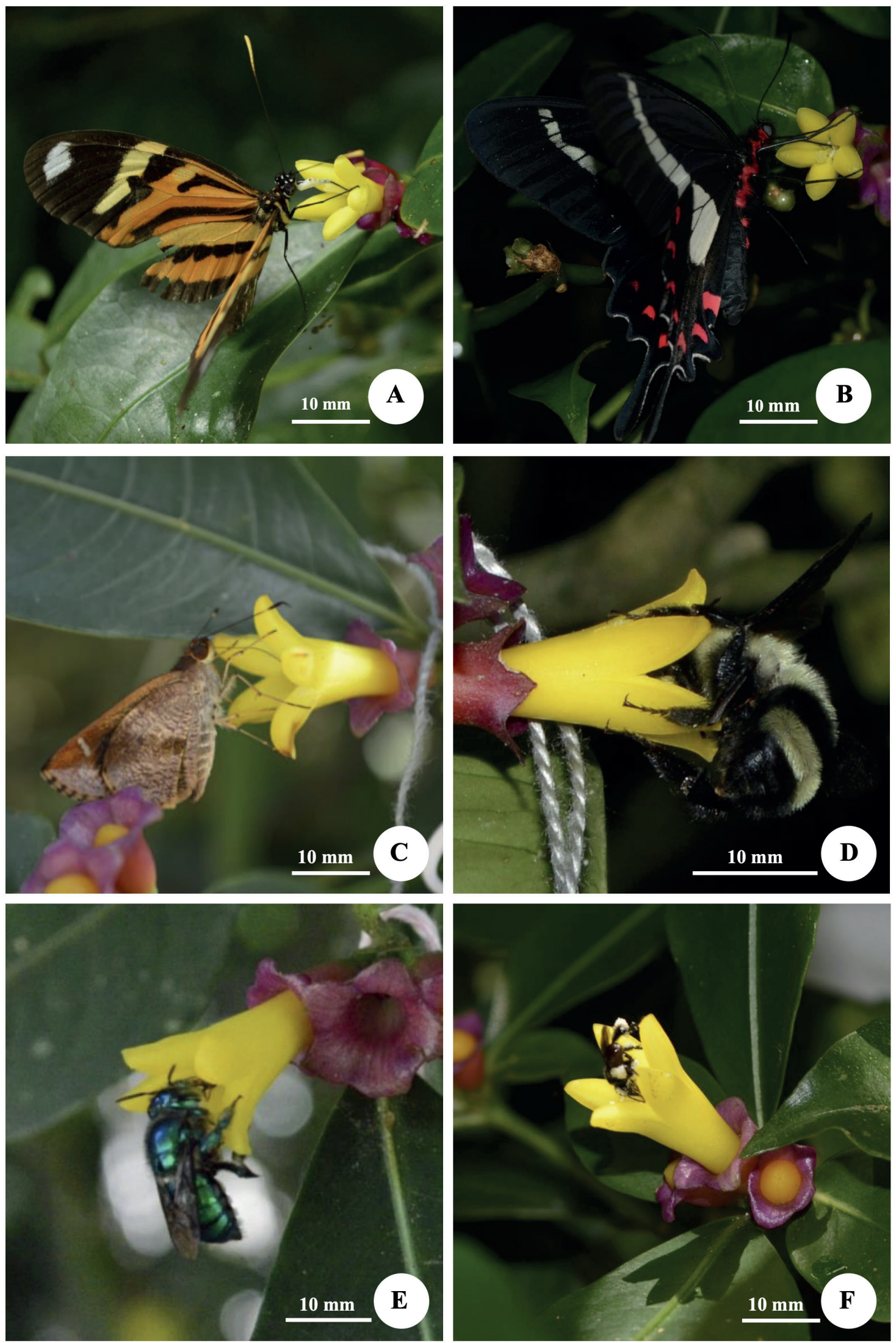

Figure 3. Floral visitors of Psychotria nuda observed in "Parque Nacional da Serra dos Órgãos" (PARNASO): (A) Heliconius narcaea; (B) Parides agavus; (C) Unidentified species of Hesperiidae; (D) Bombus brasiliensis; (E) Female Euglossa sp. collecting nectar; and (F) Trigona braueri collecting pollen. 
size. We included this stingless bee in the efficacy analyses because it could occasionally contact anthers and stigma during visits (Fig. 3F).

The relative frequency of visits differed among the functional groups of pollinators $\left(\mathrm{F}_{3,8}=16.95 ; \mathrm{p}<0.05\right)$ but not between morphs $\left(\mathrm{F}_{1,8}=2.14 ; \mathrm{p}=0.18\right.$; Fig. 4$)$, and we did not observe a significant interaction between these two variables (functional group: morph; $\mathrm{F}_{3,8}=1.05 ; \mathrm{p}=0.42$ ). Butterflies were the most frequent group and large-sized bees were more frequent than small-sized bees (Fig. 4), with the frequency of hummingbirds being intermediate between those of large- and small-sized bees but not statistically different from either (Fig. 4).

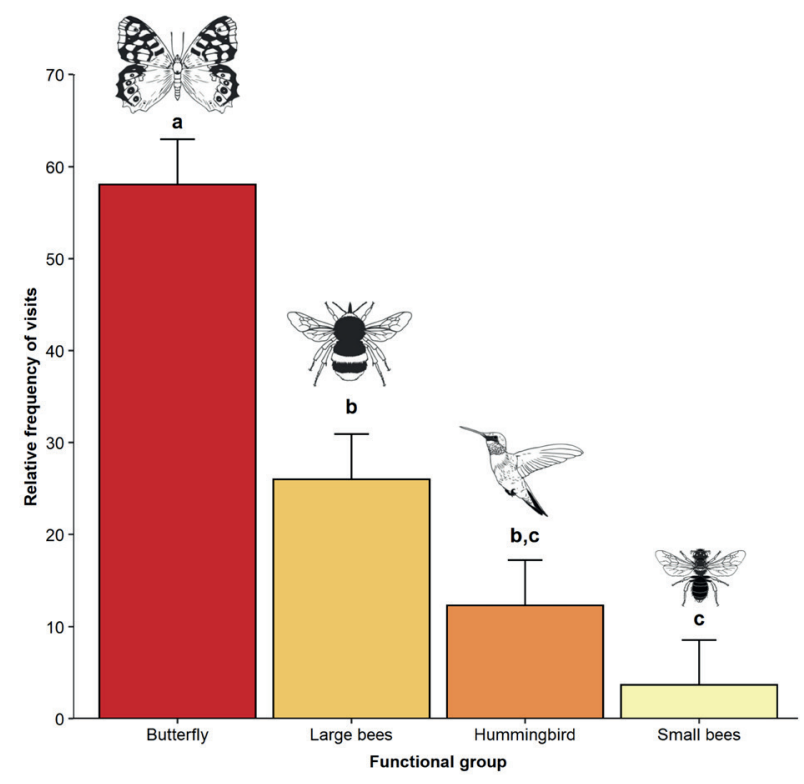

Figure 4. Relative frequency (\%) of visits of four functional groups of pollinators to flowers of Psychotria nuda in "Parque Nacional da Serra dos Órgãos" (PARNASO), Brazil. Different letters above bars represent significant differences for pairwise comparisons $(\mathrm{p}<0.05)$. The bar-plot represents the mean and the standard-error (SE). Figures of functional groups of pollinators obtained from http://plantecology.webs7.uvigo.es/.

\section{Pollinator efficacy}

A total of 82 flowers were visited during the experiment: 47 by butterflies (LS = 30 flowers; SS = 17 flowers), 23 by large-sized bees (LS = 14 flowers; SS = 9 flowers) and 12 by small-sized bees (LS = 2 flowers; $S S=10$ flowers); no flower was visited by hummingbirds during the experiment). After pollination, fruit took eight months to develop, ripening between October (2016) and February (2017), while the calyx remained persistent for ca. 10 months in flowers that did not produce fruits. Fruit set after one flower visit (i.e. pollination efficacy) did not differ between butterflies and small-sized bees (Tab. $1 ; \mathrm{X}^{2}=0.07 ; \mathrm{df}=1 ; \mathrm{p}=0.80$ ), and visits by large-sized bees did not produce fruits (Tab. 1). Fruit set of flowers exposed to a single visit ( $4.9 \%$ considering all groups) was lower than fruit set by flowers exposed to natural conditions (68.7\%; Tab. 1$)\left(X^{2}=84.70 ; d f=1\right.$; $\mathrm{p}<0.0001)$.

\section{Effect of corolla length on individual inaccuracy and reproductive success}

The relationship between corolla length and both female and male individual inaccuracies differed between the two morphs (Tab. 2; Fig. 5; 6). Individual female inaccuracy decreased with the increase of the corolla length for the SS morph but was unaffected by corolla length for the LS morph (contrasts LS-SS: $\mathrm{df}=33$; t-ratio $=2.73$; $\mathrm{p}<0.010$; Fig. 5). In contrast, while individual male inaccuracy decreased with the increase of the corolla length for the SS morph, it increased with the increase of the corolla length for the LS morph (contrasts LS-SS: $\mathrm{df}=33$; t-ratio $=5.09 ; \mathrm{p}<0.0001 ;$ Fig. 6).

We did not observe an individual effect of corolla length on plant reproductive success (corolla length: $F_{1,63}=0.005$; $\mathrm{p}=0.94$ ). However, variation in reproductive success in relation to corolla length was morph dependent (morph: $\mathrm{F}_{1,63}=5.68 ; \mathrm{p}=0.02$ ), as the interaction between the two factors was significant (corolla length: morph; $\mathrm{F}_{1,63}=5.59$; $p=0.02$ ). This relationship was positive for SS flowers and had no effect for LS flowers (Fig. 7).

\section{Discussion}

In our study with a montane population of P. nuda, we found that (1) butterflies are the main pollinators; (2) inaccuracy is higher in low organs of flowers; and (3) the longer the corolla of SS flowers, the lower the individual inaccuracy and the higher the reproductive success. We recorded visits by four functional groups of floral visitors, including small- and large-sized bees, butterflies, and hummingbirds in flowers of $P$. nuda, as have other studies conducted in lowland populations (Castro \& Araújo 2004; Almeida 2005; Ribeiro et al. 2018). However, different from these studies, which found hummingbirds to be the main pollinators (Castro \& Araújo 2004; Almeida 2005; Ribeiro et al. 2018), we found that butterflies prevailed in PARNASO over the three consecutive years of the study. This result indicates that the high frequency recorded for butterflies in PARNASO is probably not due to temporal variation of pollinators (Gómez et al. 2010; Zhao \& Huang 2013; Leal et al. 2020). Besides that, several species of hummingbirds are resident and act as pollinators of dozens of species in montane Atlantic forests (Wolowski et al. 2016), including our study site (Leal et al. 2020). In contrast to our results, a recent study observed that hummingbirds were more important than insects at higher elevations (750-950 $\mathrm{m}$ a.s.1.), whereas insects and hummingbirds were 


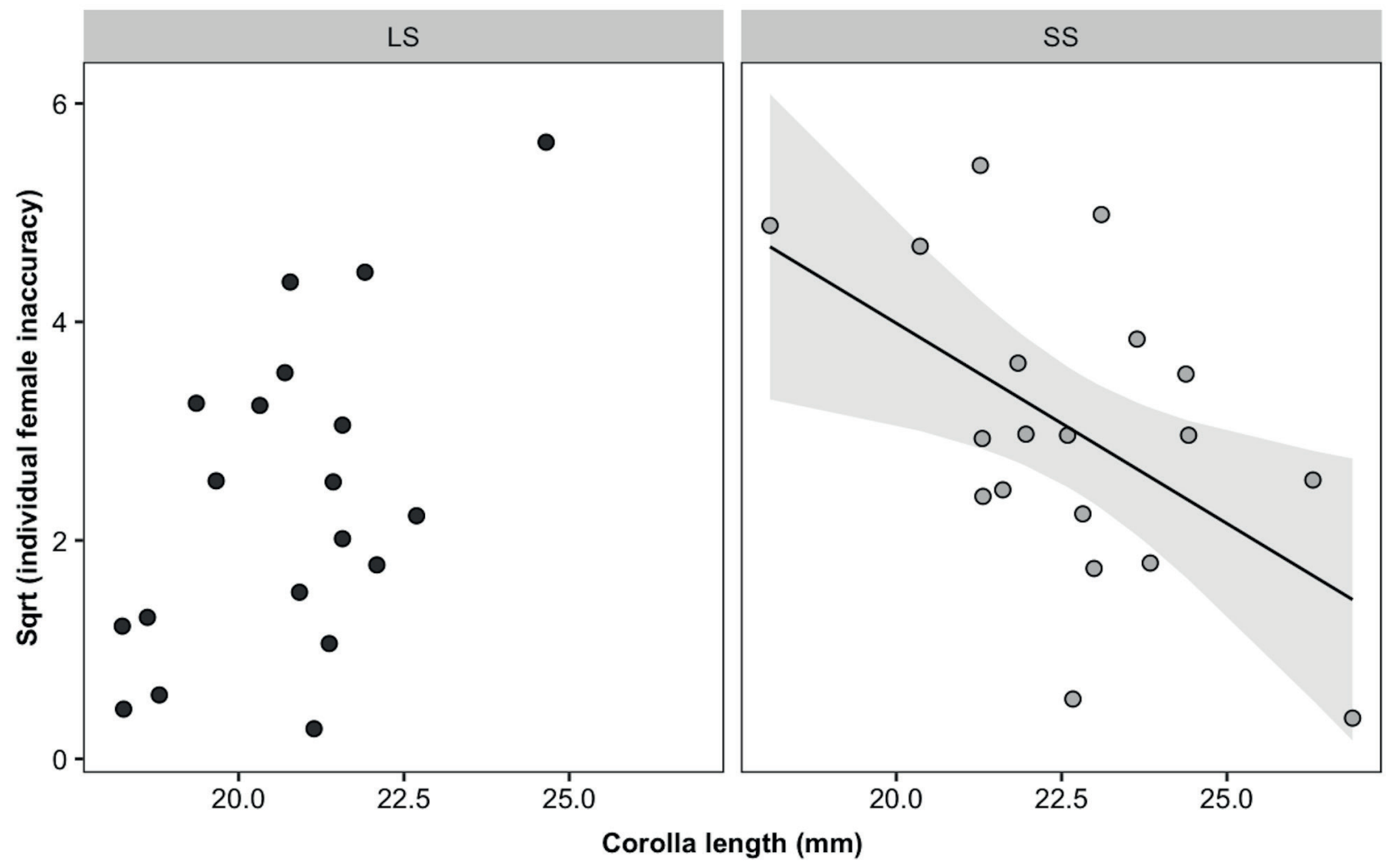

Figure 5. Relationship between individual female inaccuracy and corolla length among different morphs (LS = long-styled and SS = short-styled) of Psychotria nuda in "Parque Nacional da Serra dos Órgãos" (PARNASO), Brazil.

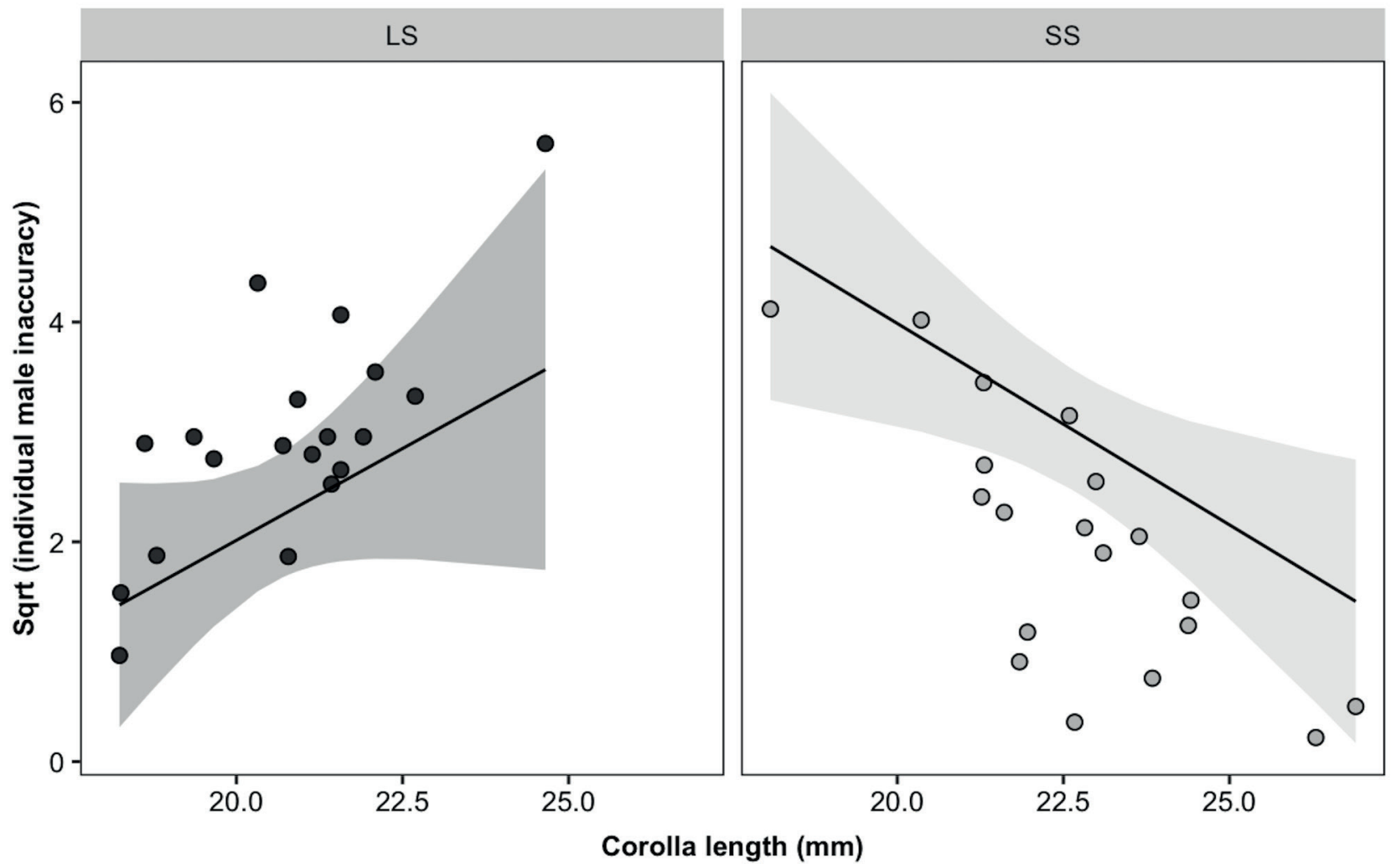

Figure 6. Relationship between individual male inaccuracy and corolla length among different morphs (LS = long-styled and SS = short-styled) of Psychotria nuda in "Parque Nacional da Serra dos Órgãos" (PARNASO), Brazil. 
equally important at mid-elevation (500-600 m a.s.1.) for some Rubiaceae species (Lehmann et al. 2019). Although elevation may have led to changes in the frequencies of pollinator functional groups visiting $P$. nuda, changes in the composition of pollinators can be influenced by several factors and at different spatial scales, so it is not possible to know, at this moment, whether the predominance of butterflies is consistent among montane populations of P. nuda. Therefore, we classify the pollination system of P. nuda as a case of functional-group generalization (sensu Armbruster 2017), but with some local specialization due to the predominance of insects or hummingbirds.

Most heterostylous plant species are visited by a broad array of floral visitors that can vary in numerous aspects

LS

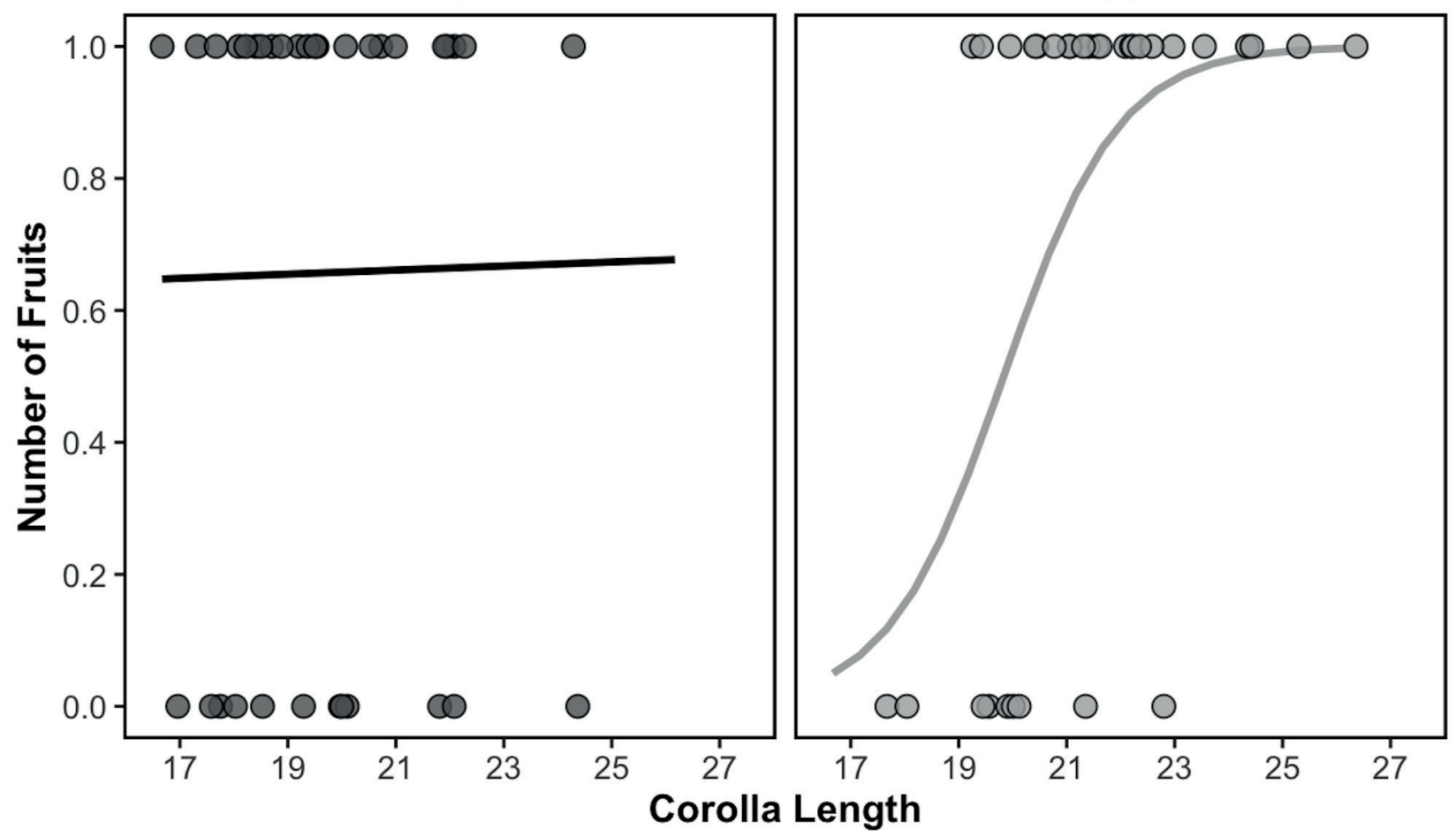

Figure 7. Relationship between fruit production under natural conditions and corolla length among different morphs (LS = longstyled and SS = short-styled) of Psychotria nuda in "Parque Nacional da Serra dos Órgãos" (PARNASO), Brazil.

Table 1. Pollination efficacy (fruit set after a single visit) by different functional groups of visitors and pollination effectiveness (fruit set after flower exposure to natural conditions for the entirety of anthesis) in flowers of Psychotria nuda in "Parque Nacional da Serra dos Órgãos" (PARNASO).

\begin{tabular}{|c|c|}
\hline Floral visitor & Fruit set (fruits/flowers) \\
\hline Butterfly & $6.4 \%(3 / 47)$ \\
\hline Large-bee & $0(0 / 22)$ \\
\hline Small-bee & $8.33 \%(1 / 12)$ \\
\hline Natural conditions & $68.7 \%(46 / 67)$ \\
\hline
\end{tabular}

Table 2. Results of analysis of variance (ANOVA) displaying the effects of floral morph and corolla length on the female and male inaccuracy distylous Psychotria nuda in "Parque Nacional da Serra dos Órgãos" (PARNASO).

\begin{tabular}{|c|c|c|c|}
\hline & df & F value & P \\
\hline Female inaccuracy & & & \\
\hline Corolla length & 1 & 2.430 & 0.129 \\
\hline Morph & 1 & 8.545 & 0.006 \\
\hline Corolla length: Morph & 1 & 7.427 & 0.010 \\
\hline Residual & 33 & & \\
\hline Male inaccuracy & & & 0.011 \\
\hline Corolla length & 1 & 7.311 & $<.0001$ \\
\hline Morph & 1 & 24.523 & $<.0001$ \\
\hline
\end{tabular}




\section{Divergent pollination system and morph-dependent effects of corolla length on inaccuracy of reciprocity and reproductive success of a distylous species of Rubiaceae}

(e.g., foraging behavior, body size, and mouthpart length) that can influence efficacy (Deschepper et al. 2018). Based on our pollinator efficacy experiments, we observed that butterflies and small-sized bees did not differ in efficacy, while we did not obtain information for large-sized bees (due to low fruit production after a single visit) or hummingbirds (due to the low frequency of visits during the experiment). In a lowland population of $P$. nuda on an island ca. 150 km from PARNASO ("Parque Estadual da Ilha Grande"), $18.4 \%$ of flowers were found to set fruit after a single visit by hummingbirds (Almeida 2005), while the values of fruit set after a single visit by insects ( $4.4 \%$ of flowers; Almeida 2005) were similar to what we registered in our study $(6.4 \%)$. These results indicate that, in lowlands, hummingbirds carry greater loads of cross-pollen of $P$. nuda than do insects (Ashworth et al. 2015), and that the low efficacy of insects may be related to their foraging behavior favoring intramorph-pollen deposition. Despite the low efficacy after a single visit, we found that roughly $69 \%$ of $P$. nuda flowers exposed to natural conditions at PARNASO produced fruits, which was similar to the fruit production found on Ilha Grande where $42 \%$ of the flowers set fruit in natural conditions and hummingbirds prevailed (Almeida 2005). Thus, we conclude that butterflies may be responsible for the high fruit set observed in natural conditions and that the low efficacy of this group may be compensated by their high visitation frequency (i.e., high effectiveness; sensu Freitas 2013).

The theoretical expectations of perfect reciprocity in heterostylous plants are related to the fact that variation in reciprocity could lead to low rates of disassortative pollination (Keller et al. 2014). Despite this expectancy, variation in the degree of reciprocal herkogamy has been reported for different distylous species (Ree 1997; Faivre \& McDade 2001; Keller et al. 2014) including P. nuda (Castro \& Araújo 2004; Almeida 2005; Klein 2007). In addition, variation in the degree of inaccuracy between high and low floral structures are common and recent studies observed greater inaccuracy in high-level than in low-level organs (Armbruster et al. 2017; Jacquemyn et al. 2018; Brys \& Jacquemyn 2019; Furtado 2019; Matias et al. 2020). Differing from these studies, we found $P$. nuda to present greater inaccuracy for low organs, which is a less observed pattern among other species Psychotria (see supplementary material in Furtado 2019).

Variation in the degree of inaccuracy due to morphological variation in floral traits may affect the reproductive success of distylous plants (Matias et al. 2020). Corolla tube length may be one of the main morphological factors affecting inaccuracy (Sá et al. 2016; Furtado 2019), mainly for distylous plants with epipetalous stamens (Thompson \& Dommée 2000; Castro \& Araújo 2004; Keller et al. 2012; Sá et al. 2016). The effect of variation in the corolla may differ between morphs, resulting in morph-specific selection on this trait (Li et al. 2017). We observed an effect of corolla length on individual male and female inaccuracies in P. nuda, with this relationship being negative for the SS morph, increasing reciprocity in both directions, and positive for LS flowers, decreasing reciprocity. Moreover, our results showed a positive relationship between corolla length and fruit-set within SS flowers. These results support the idea that individual levels of inaccuracy affects legitimate pollen deposition; and that deviations from perfect reciprocity can have a greater effect on SS individuals than on LS individuals due the greater difficulty of accessing the stigmas included in the tubular corolla (Brys \& Jacquemyn 2019).

Studies on pollination biology in Brazil are generally carried out at a single site, even for plant species with populations distributed across large geographic ranges (but see Alves-dos-Santos 2002; Rech et al. 2018). Interestingly, several independent reproductive studies have been carried out in different populations of P. nuda (Castro \& Araújo 2004; Almeida 2005; Pereira et al. 2006; Klein 2007; Ribeiro et al. 2018), the results of which support the idea that interpopulation variation in pollination systems may be common. Exploring spatial variation of pollination systems can lead to a better understanding of the ecology and evolution of floral traits and plant-pollinator interactions (Thompson 2005; Herrera et al. 2006).

\section{Acknowledgements}

We thank ACR Peixoto and IM Kessous for field support; NAC Marino for analysis support; A Soares for butterfly identification; E Wild for language editing; PARNASOICMBio for permission and support; CAPES for awarding a MSc. scholarship (PPG Botânica - JBRJ) to the first author; CNPq for a PQ scholarship to L Freitas and for funding the project (PVE 400789/2014-0); and FAPERJ for a CNE scholarship to L Freitas.

\section{References}

Abdusalam A, Liao WJ, Zhang ZQ, Li QJ. 2020. Pollinator shifts along an elevation gradient mediate different response in self-pollination in heterostylous Primula nivalis. Journal of Systematics and Evolution 12639. doi.org/10.1111/jse.12639

Almeida EM, Alves MAS. 2000. Fenologia de Psychotria nuda e P. brasiliensis (Rubiaceae) em uma área de Floresta Atlântica do Sudeste do Brasil. Acta Botanica Brasilica 14: 335-346.

Almeida EM. 2005. Ecologia reprodutiva e comportamento dos visitantes florais e dos frugívoros em duas espécies de Psychotria L. (Rubiaceae) em uma área de Floresta Atlântica, Ilha Grande, Rio de Janeiro. PhD Thesis, Universidade do Estado do Rio de Janeiro, Rio de Janeiro.

Alves-dos-Santos I. 2002. Flower-visiting bees and the breakdown of the tristylous breeding system of Eichhornia azurea (Swartz) Kunth (Pontederiaceae). Biological Journal of the Linnean Society 77: 499-507.

Armbruster WS. 2017. The specialization continuum in pollination systems: diversity of concepts and implications for ecology, evolution and conservation. Functional Ecology 31: 88-100.

Armbruster WS, Bolstad GH, Hansen TF, Keller B, Conti E, Pélabon C. 2017. The measure and mismeasure of reciprocity in heterostylous flowers. New Phytologist 215: 906-917. 
Ashworth L, Aguilar R, Martén-Rodríguez S, et al. 2015. Pollination syndromes: A global pattern of convergent evolution driven by the most effective pollinator. In: Pontarotti P. (ed.) Evolutionary biology: Biodiversification from genotype to phenotype. New York, Springer Cham. p. 203-224.

Barrett SCH, Richards JH. 1990. Heterostyly in tropical plants. Memoirs of the New York Botanical Garden 55: 35-61.

Barrett SCH, Jesson LK, Baker AM. 2000. The evolution and function of stylar polymorphism in flowering plants. Annals of Botany 85: 253-265.

Barrett SCH. 2002. The evolution of plant sexual diversity. Nature Genetics 3: $274-284$.

Barrett SCH, Shore JS. 2008. New Insights on Heterostyly: Comparative Biology, Ecology and Genetics. In: Franklin-Tong VE. (ed.) Selfincompatibility in flowering plants-evolution, diversity, and mechanisms. Berlin, Springer-Verlag. p. 3-32.

Bates D, Mächler M, Bolker B, Walker S. 2015. Fitting linear mixed-effects models using lme4. Journal of Statistical Software 67: 1-48.

Bergamo PJ, Rech AR, Brito VL, Sazima M. 2016. Flower colour and visitation rates of Costus arabicus support the 'bee avoidance' hypothesis for red-reflecting hummingbird-pollinated flowers. Functional Ecology 30: 710-720.

BFG. 2015. Growing knowledge: an overview of seed plant diversity in Brazil. Rodriguésia 66: 1085-1113.

Brys R, Jacquemyn H. 2019. The impact of individual inaccuracy of reciprocal herkogamy on legitimate pollen deposition and seed set in a distylous self-incompatible herb. Journal of Ecology 108: 81-93.

Castro CC, Araújo AC. 2004. Distyly and sequential pollinators of Psychotria nuda (Rubiaceae) in the Atlantic rain forest, Brazil. Plant Systematics and Evolution 244: 131-139.

Darwin C. 1877. The different forms of flowers on plants of the same species. London, John Murray.

Deschepper P, Brys R, Jacquemyn H. 2018. The impact of flower morphology and pollinator community composition on pollen transfer in the distylous Primula veris. Botanical Journal of the Linnean Society 186: 414-424.

Faivre AE, McDade LA. 2001. Population-level variation in the expression of heterostyly in three species of Rubiaceae: Does reciprocal placement of anthers and stigmas characterize heterostyly?. American Journal of Botany 88: 841-853.

Frankie GW, Haber WA, Opler PA, Bawa KS. 1983. Characteristics and organization of the large bee pollination system in the Costa Rican dry forest. In: Jones CE, Little RJ. (eds.) Handbook of experimental pollination biology. Van Nostrand, Reinhold Inc. p. 411-447.

Freitas L. 2013. Concepts of pollinator performance: is a simple approach necessary to achieve a standardized terminology?. Brazilian Journal of Botany 36: 3-8.

Fox J, Weisberg S. 2019. An \{R\} Companion to Applied Regression, 2nd. edn. Thousand Oaks, Sage. http://socialsciences.mcmaster.ca/jfox/ Books/Companion/. 04 Jan. 2021.

Furtado MTR. 2019. Biologia da polinização de Palicourea Aubl. e Psychotria L. (Rubiaceae): variações e funcionalidade da hercogamia recíproca e dos polinizadores. PhD Thesis, Universidade de Brasília, Brasília.

Furtado MT, Matias R, Pérez-Barrales R, Consolaro H. 2021. Do reciprocal herkogamy and pollinators affect legitimate pollen flow in distylous species of Rubiaceae?. Botanical Journal of the Linnean Society boab004. doi: 10.1093/botlinnean/boab004

Ganders FR. 1979. The biology of heterostyly. New Zealand Journal of Botany 17: 607-635.

Gómez JM, Abdelaziz M, Lorite J, Muñoz-Pajares AJ, Perfectti F. 2010. Changes in pollinator fauna cause spatial variation in pollen limitation. Journal of Ecology 98: 1243-1252.

Hamilton CW. 1990. Variations on a distylous theme in a Mesoamerican Psychotria subgenus Psychotria (Rubiaceae). Memoirs of the New York Botanical Garden 55: 62-75.

Harder LD, Johnson SD. 2009. Darwin's beautiful contrivances: evolutionary and functional evidence for floral adaptation. New Phytologist 183: 530-545.

Herrera CM. 2009. Multiplicity in unity: plant subindividual variation and interactions with animals. Chicago, University of Chicago Press.
Herrera CM, Castellanos MC, Medrano M. 2006. Geographical context of floral evolution: towards an improved research programme in floral diversification. In: Harder LD, Barrett SCH. (eds.) Ecology and evolution of flowers. Oxford, Oxford University Press. p. 278-294.

Inouye DW. 1980. The terminology of floral larceny. Ecology 61: 1251-1253.

Jacquemyn H, Gielen M, Brys R. 2018. Is sexual organ reciprocity related to legitimate pollen deposition in distylous Pulmonaria (Boraginaceae)?. Oikos 127: 1216-1224.

Johnson SD, Steiner KE. 2000. Generalization versus specialization in plant pollination systems. Trends in Ecology \& Evolution 15: 140-143.

Keller B, Vos JM, Conti E. 2012. Decrease of sexual organ reciprocity between heterostylous primrose species, with possible functional and evolutionary implications. Annals of Botany 110: 1233-1244.

Keller B, Thomson JD, Conti E. 2014. Heterostyly promotes disassortative pollination and reduces sexual interference in Darwin's primroses: evidence from experimental studies. Functional Ecology 28: 14131425.

Klein DE. 2007. Estudo do sistema heteromórfico de auto-incompatibilidade em uma população de Psychotria nuda (Cham. \& Schlecht.) Wawra (Rubiaceae): morfologia floral; sucesso reprodutivo; aspectos celulares e teciduais; e análise da composição protéica de partes florais. $\mathrm{PhD}$ Thesis, Universidade Estadual do Norte Fluminense Darcy Ribeiro, Campos dos Goytacases.

Klein DE, Freitas L, Da Cunha M. 2009. Self-incompatibility in a distylous species of Rubiaceae: is there a single incompatibility response of the morphs?. Sexual Plant Reproduction 22: 121-131.

Köppen W, Geiger R. 1928. Klimate der Erde. Wall-map 150cmx200cm. Gotha, Germany, Verlag Justus Perthes Publishers.

Lenth R. 2019. emmeans: Estimated Marginal Means, aka Least-Squares Means. R package version 1.4.3. https://CRAN.R-project.org/ package=emmeans. 04 Jan. 2021.

Leal RLB, Moreira MM, Pinto AR, Ferreira JO, Rodríguez-Gironés M, Freitas L. 2020. Temporal changes in the most effective pollinator of a bromeliad pollinated by bees and hummingbirds. PeerJ 8: e8836. doi: $10.7717 /$ peerj. 8836

Lehmann LJ, Maruyama PK, Bergamo PJ, Maglianesi MA, Rahbek C, Dalsgaard B. 2019. Relative effectiveness of insects versus hummingbirds as pollinators of Rubiaceae plants across elevation in Dominica, Caribbean. Plant Biology 21: 738-744.

Li HD, Zhao YH, Ren ZX, et al. 2017. Fitness-related selection on floral traits in the distylous plant Primula poissonii (Primulaceae). Journal of Plant Ecology 10: 559-568.

Matias R, Pérez-Barrales R, Consolaro H. 2020. Patterns of variation in distylous traits and reproductive consequences in Erythroxylum species and populations. American Journal of Botany 107: 1-13.

Naiki A. 2012. Heterostyly and the possibility of its breakdown by polyploidization. Plant Species Biology 27: 3-29.

Navarro L, Guitián J. 2002. The role of floral biology and breeding system on the reproductive success of the narrow endemic Petrocoptis viscosa Rothm. (Caryophyllaceae). Biological Conservation 103: 125-132.

Ollerton J, Killick A, Lamborn E, Watts S, Whiston M. 2007. Multiple meanings and modes: on the many ways to be a generalist flower. Taxon 56: 717-728.

Pereira ZV, Vieira MF, Carvalho-Okano RM. 2006. Fenologia da floração, morfologia floral e sistema de incompatibilidade em espécies distílicas de Rubiaceae em fragmento florestal do Sudeste brasileiro. Brazilian Journal of Botany 29: 471-480.

Pérez-Barrales R, J Arroyo, WS Armbruster. 2007. Differences in pollinator faunas may generate geographic differences in floral morphology and integration in Narcissus papyraceus (Amaryllidaceae). Oikos 116: 1904-1918.

R Development Core Team. 2019. R: A Language and Environment for Statistical Computing. Vienna, R Foundation for Statistical Computing, Austria. http://www.Rproject.org/. 04 Jan. 2021.

Rech AR, Jorge LR, Ollerton J, Sazima M. 2018. Pollinator availability, mating system and variation in flower morphology in a tropical savanna tree. Acta Botanica Brasilica 32: 462-472.

Ree RH. 1997. Pollen flow, fecundity, and the adaptative significance of heterostyly in Palicourea padifolia (Rubiaceae). Biotropica 29: 298-308. 


\section{Divergent pollination system and morph-dependent effects of corolla length on inaccuracy of reciprocity and reproductive success of a distylous species of Rubiaceae}

Ribeiro CL, Melo Jr JCF, Mouga MDS, Carneiro E. 2018. Fenologia e visitantes florais de Psychotria nuda (Rubiaceae) em um fragmento urbano de Mata Atlântica no sul do Brasil. Neotropical Biology \& Conservation 13: 192-201.

Sá T, Furtado MT, Ferrero V, Pérez-Barrales R, Rodrigues EB, Santos IG, Consolaro H. 2016. Floral biology, reciprocal herkogamy and breeding system in four Psychotria species (Rubiaceae) in Brazil. Botanical Journal of the Linnean Society 182: 689-707.

Santamaría L, Rodríguez-Gironés MA. 2015. Are flowers red in teeth and claw? Exploitation barriers and the antagonist nature of mutualisms. Evolutionary Ecology 29: 311-322.

Thompson JD, Dommée B. 2000. Morph-specific patterns of variation in stigma height in natural populations of distylous Jasminum fruticans. New Phytologist 148: 303-314.

Thompson JD. 2001. How do visitation patterns vary among pollinators in relation to floral display and floral design in a generalist pollination system?. Oecologia 126: 386-394.

Thompson JN. 2005. The geographic mosaic of coevolution. Chicago, University of Chicago Press.
Van der Niet T, Johnson SD. 2012. Phylogenetic evidence for pollinatordriven diversification of angiosperms. Trends in Ecology \& Evolution 27: 353-361

Veloso HP, Rangel Filho ALR, Lima JCA. 1991. Classificação da vegetação brasileira adaptada a um sistema universal. Rio de Janeiro, Fundação IBGE.

Waser NM. 2006. Specialization and generalization in plant-pollinator interactions: an historical perspective. In: Waser NM, Ollerton J. (eds.) Plant-pollinator interactions: from specialization to generalization. Chicago, University of Chicago Press. p. 3-17.

Webb CJ, Lloyd DG. 1986. The avoidance of interference between the presentation of pollen and stigmas in angiosperms II. herkogamy. New Zealand Journal of Botany 24: 163-178.

Wolowski M, Nunes CEP, Amorim FW, et al. 2016. Interações plantapolinizador em vegetação de altitude na Mata Atlântica. Oecologia Australis 20: 7-23.

Zhao ZG, Huang SQ. 2013. Differentiation of floral traits associated with pollinator preference in a generalist-pollinated herb, Trollius ranunculoides (Ranunculaceae). International Journal of Plant Sciences 174: 637-646. 